\title{
Individual Tariffs for Mobile Services: Analysis of Operator Business and Risk Consequences
}

\author{
Hong Chen and Louis-Francois Pau
}

\begin{tabular}{|l|l|}
\hline \multicolumn{2}{|l|}{ ERIM REPORT SERIES RESEARCH IN MANAGEMENT } \\
\hline ERIM Report Series reference number & ERS-2007-052-LIS \\
\hline Publication & August 2007 \\
\hline Number of pages & 7 \\
\hline Persistent paper URL & \\
\hline Email address corresponding author & hchen@rsm.nl \\
\hline Address & Erasmus Research Institute of Management (ERIM) \\
& RSM Erasmus University / Erasmus School of Economics \\
& Erasmus Universiteit Rotterdam \\
& P.O.Box 1738 \\
& 3000 DR Rotterdam, The Netherlands \\
& Phone: $\quad+31104081182$ \\
& Fax: $\quad+31104089640$ \\
& Email: info@erim.eur.nl \\
& Internet: $\quad$ www.erim.eur.nl \\
\hline
\end{tabular}

Bibliographic data and classifications of all the ERIM reports are also available on the ERIM website: www.erim.eur.nl 


\section{ERASMUS RESEARCH INSTITUTE OF MANAGEMENT}

\section{REPORT SERIES}

\section{RESEARCH IN MANAGEMENT}

\begin{tabular}{|l|l|}
\hline \multicolumn{2}{|l|}{ ABSTRACT AND KEYWORDS } \\
\hline Abstract & $\begin{array}{l}\text { A design approach is offered for individual tariffs for mass customized mobile service products, } \\
\text { whereby operators can determine their contract acceptance rules to guarantee with a set } \\
\text { probability their minimum profit and risk levels. It uses realistic improvements to earlier reported } \\
\text { negotiation algorithms [1], and a full operator operational model including infrastructure and } \\
\text { content acquisition. Value at risk and profit are analyzed when a random user has consistent } \\
\text { characteristics to a survey group, so that risk and profits are pooled. This analysis is necessary } \\
\text { to give the supplier business guarantees to enter individual tariff agreements. A full numerical } \\
\text { case is given for a class of mobile service. }\end{array}$ \\
\hline Free Keywords & Individual tariffs, mobile communication services, risks \\
\hline Availability & $\begin{array}{l}\text { The ERIM Report Series is distributed through the following platforms: } \\
\text { Academic Repository at Erasmus University (DEAR), DEAR ERIM Series Portal } \\
\text { Social Science Research Network (SSRN), SSRN ERIM Series Webpage } \\
\text { Research Papers in Economics (REPEC), REPEC ERIM Series Webpage }\end{array}$ \\
\hline Classifications & $\begin{array}{l}\text { The electronic versions of the papers in the ERIM report Series contain bibliographic metadata } \\
\text { by the following classification systems: } \\
\text { Library of Congress Classification, (LCC) } \underline{\text { LCC Webpage }} \\
\text { Journal of Economic Literature, (JEL), JEL Webpage } \\
\text { ACM Computing Classification System CCS Webpage } \\
\text { Inspec Classification scheme (ICS), ICS Webpage }\end{array}$ \\
\hline
\end{tabular}




\title{
Individual Tariffs for Mobile Services: Analysis of Operator Business and Risk Consequences
}

\author{
H. Chen, L-F Pau \\ Rotterdam School of Management, Erasmus University, the Netherlands \\ \{hchen,lpau\}@rsm.nl
}

\begin{abstract}
A design approach is offered for individual tariffs for mass customized mobile service products, whereby operators can determine their contract acceptance rules to guarantee with a set probability their minimum profit and risk levels. It uses realistic improvements to earlier reported negotiation algorithms [1], and a full operator operational model including infrastructure and content acquisition. Value at risk and profit are analyzed when a random user has consistent characteristics to a survey group, so that risk and profits are pooled. This analysis is necessary to give the supplier business guarantees to enter individual tariff agreements. A full numerical case is given for a class of mobile service.
\end{abstract}

\section{Introduction}

Mass customized mobile service products (also called in short form: individual tariffs) in telecommunications refer to the regulatory protected ability for an identified user to obtain from a service provider, by a bilateral specific contract, a unique service specific price corresponding to an individual request from the user specified with personalized service demand attributes and some duration [2].

This research is carried out under the assumption that the market is fully competitive and customer/usercentered. Our previous work studied the negotiation between a fictive user and a fictive simplified supplier [1]; the results showed that the implementation of individual tariffs can have a win-win or win-lose outcome when compared to the general public tariff offer. The current paper goes one step further by studying the negotiation between one user belonging to a survey group sharing some common features, and the close-to-real operational model of one mobile communication and content supplier. This model includes, amongst other features, the investments and provisioning costs for content, besides adaptation of the transmission technology to user-defined QoS parameters.

The first goal of this paper is to study the equilibrium/equilibria of the negotiation games under the above close to real situation. The second goal is to help the operator as supplier of individual tariff to design the individual tariff contract acceptance decision criteria when, facing the variability of individual needs, he pools a group of diverse individual users together in order to make a positive profit with a high likelihood and with acceptable risk.

The rest of the paper is organized as follows: Section 2 introduces the underlying negotiation model between one individual user and a supplier. Section 2.1 describes the non-linear business model of a supplier; Section 2.2 presents a discretized negotiation algorithm which is suitable for real implementation as some contract features (like duration) can only be integers. Section 3 addresses the negotiations between a supplier and a user belonging to a survey group. A risk measurement approach is introduced so that the supplier can adjust contract acceptance parameters to achieve with some probability minimum profit and risk levels. Section 4 applies the approach to a specific mass customized service product; a numerical case is analyzed and the results are presented. Section 5 concludes the paper.

\section{Underlying negotiation model}

The economic and social incentives of users and suppliers to adopt/provide personalized services combined with individual tariffs are analyzed in [2]. The theoretical framework of individual tariffs was built based on the behavioral models of the users and the suppliers, drawing extensively on economics, psychology, and sociology literature [2]. A computational model was proposed in [1], where user and supplier exchange technical, service and price attributes of a value added mobile service, in a "service design space". The supplier announces the offering of a service; he publishes a set of services attributes with 
corresponding values, including a price (public offer). A user who is not satisfied with the public offer can start a recursive Stackelberg game, where the user and the supplier take turns to optimize their own utilities in each stage of the game. We define an equilibrium as a situation in which both the user and the supplier are satisfied with the negotiation result and agree to sign a contract.

The user makes decisions in a "perceptual space", which is a e.g. 2-3 dimensional space compressed from the larger "service design space" designed by the common service demands across the survey group he belongs to. In this way, the user can individually make simple visible decisions, and will try to minimize the distance between a point ideal to him (target point) and the current negotiation status. Some of user's constraints are dynamic and depend on the input from the previous round from the supplier. The mapping relation between the two spaces is service specific; it is derived from a user survey and a statistical technique called Principle Component Analysis (PCA); the coefficients are called PCA loadings [3]. Other data dimensional reduction technique such as correspondence analysis can also be used but their statistical properties are lesser known then needed in later risk analysis.

The supplier makes decision in the "service design space". His decision variables are primarily related to technical attributes (e.g. related to QoS) and are different from user's decision variables. The supplier's utility function is defined as the incremental profit from serving the demand of an additional user. The supplier's goal is to maximize his profit. The supplier also has constraints. Some of them are dynamic (iteration dependent). The supplier updates the constraints based on the signals he receives during the negotiation.

\subsection{A non-linear business model of network and content provider}

Representing a vast improvement on the supplier (operator) model used in [1] ,this paper has been using a recent detailed close-to-real model of service related capital expenditures (CAPEX), operations expenditures (OPEX), and content acquisition costs and revenues. This model addresses the incremental costs and revenues from value added services and is rather generic for mobile services. The incremental revenue is mainly decided by the price the incremental user intends to pay, and by the contract duration, for the service corresponding to user requested set of characteristics. On the cost side, CAPEX is accrued in proportion to depreciation of incremental facilities during the contract duration with the client, and likewise for OPEX.

Regarding specific features of this model there are first the non-linearities linked to the necessary wireless links, transmission and switching/routing characteristics with a possible switching between $2 \mathrm{G}$, $3 \mathrm{G}$ and broadband generic access; the corresponding infrastructure needs based on traffic requirements derived from the value-added service attributes are taken into account. Next, the model handles the service specific CRM, OSS, content storage, and billing aspects besides handling the eventual manpower costs involved in tutoring as in the mSinging service case (see Section 4 for details). Inspired by the production functions used in microeconomics, OPEX is estimated by a non-linear service provisioning production and cost function with explicit marginal elasticities and production factor substitution. Finally if the operator invests in content creation in connection with one or several value-added services using said content, revenues from it for the contract duration are accrued.

In summary, the inputs of the model are user's requests on the service attributes (including price and contract duration), and the output is the operator's incremental operational profit before overheads (financial, administration, marketing etc.) from that user. The design of the model was estimated from real systems supplier data and further parameters were fit to real operator operations for a typical mobile operator's geographical coverage. In view of its complexity and proprietary elements, we omit the detailed specification.

\subsection{Algorithm with discretization}

The non-linearity of the cost and revenue structure of the supplier makes it difficult to build the model using one simple mathematical formula. Thus our model is built using spreadsheets. Next, some of the decision variables in the model should take only integer or discrete values to be meaningful (e.g. 1 month but not 0.9 month). Most of the commercial optimization software requires an explicit target function and takes continuous real values; therefore they can not be used in our case.

To compute a function that has both discrete variables and continuous variables, we discretize all variables and conduct an exhaustive search of the respective optima by trying all combinations of the discretized values of each variable subject to user or supplier constraints. Discretization takes several steps:

1. Generate sub-intervals for each variable based on its feasible region and a chosen number of intervals. The feasible region of a variable corresponds to the meaningful range of a service attribute. The number of 
intervals is the same for all variables in one computation.

2. Generate representing values for sub-intervals. There are three conventions to generate the representing values: left edge/center/right edge, which take the smallest/median/highest value of each subinterval correspondingly. During one computation, only one convention should be used.

3. Map a variable to a representing value. When the value of a variable falls within a sub-interval, it will be mapped onto the real value representative of this subinterval.

For the continuous variables, the result of the computation can be used directly and makes sense in terms of the service attribute that it represents. Their relative error is proportional to the discretization rate. For discrete variables, the discretization mostly leads to a real or fractional value. Thus the result needs to be rounded up to have a meaningful interpretation. The relative error is not only proportional to discretization rate but also related to the method of rounding applied to the result.

The discretization rate can be indicated by the number of intervals. When the discretization rate is low, the discretization significantly reduces the number of possible values of each variable. This greatly reduces the computational complexity. But it is at the expense of less accurate results. The results are more of a qualitative indication of the service attributes rather than a quantitative one. When the discretization rate becomes higher, the result becomes more accurate and thus gives a quantitative indication of the values of the service attributes.

In our computation, the user's target point is not discretized. Given that the user can take only discretized values, it is possible that the user can not reach the target point (distance to target point $\neq 0$ ) when all the constraints are slack. The constraints of both the user and the supplier are not discretized.

The inputs consist of all the possible combinations of the discretized values of each variable. All the inputs will first undergo binary constraint checking. The inputs violating the constraints are excluded. Each input generates one output. The optimal result is the input that generates the maximum output, which is obtained from ranking all the outputs. If the maximum value corresponds to multiple identical outputs, we can either randomly choose one input that leads to the maximum value, or choose an input by giving priority rules to certain variables.

The objective functions of the user and the supplier are continuous functions in mathematical terms; except for the discretization and using exhaustive search instead of algorithmic optimization, the negotiation algorithm is the same as in [1].
User's decision rules are:

1. If the current optimization result is worse than the utility that he elicits from public offer, quit;

2. If no solution has been found after two consecutive rounds of optimization, quit. No solution here means that user's constraints exclude all the inputs.

3. Otherwise, continue; Supplier decision rules are:

1. If there is no difference between two consecutive optimization results of the supplier and supplier's utility from the user's request $\geq$ profit threshold, sign the contract and quit;

2. If there is no difference between the two consecutive optimization results of the supplier and supplier's utility from the user's request < profit threshold, quit without signing;

3. If oscillation happens and the supplier's utility from user's request $\geq$ profit threshold, sign the contract and quit;

4. If oscillation happens and the supplier's utility from user's request $<$ profit threshold, quit without signing;

5. Otherwise, continue.

Here "profit threshold" is a parameter upon which the supplier decides whether to sign the contract or not during the negotiation with a single user.

\section{Risk Pooling}

To provide personalized services and individual tariffs, the supplier negotiates with each user separately. The result of the negotiation, if successful, is a set of service attributes with user-specific values and a corresponding user-specific tariff. As a consequence, the supplier makes different profits when serving different users. Some generate positive profits; others may generate loss at an individual contract level.

In order to have a robust business, the supplier first needs to have a positive expected profit across the subscriber-base. More precisely, the expected profit from all subscribers of individual tariffs must be nonnegative, and the contract number must be non zero. Second, the probability of not reaching the expected profit should be small and less than a given threshold.

Compared to public tariffs, individual tariffs allow higher volatility of profit, which means higher risk to the supplier. But a supplier often has a large user-base even for a specific value added service. The risk from individual users can be mitigated by pooling the random profits across a user-base for that (class of) service offer. Here the assumption is that the risks from individual users are uncorrelated or have a low degree 
of correlation. Furthermore, the supplier can set certain parameters of the decision rules, which decline extreme requests from the user. However such decision rules and the contract terms must not be so greedy that none of the potential adopters agree to sign an individual contract. Thus it is necessary to have a tool to calculate the expected profit and to measure the risk so that the supplier can adjust the parameters in his decision criteria according to his risk policy.

A standard benchmark of risk is Value at Risk $(\mathrm{VaR})$, which offers a statistical summary of risk. The concept is quite simple: for a given time horizon $t$, and the confidence level $p$, the value at risk is the amount of loss of the supplier over the time horizon $t$ that is exceeded with probability $\mathrm{p}$. In essence, it answers one simple question: "how bad can things get"?[4]. The idea behind $\mathrm{VaR}$ is to compute the value being measured (return, profit, etc) with regard to distribution of the risk factors. A risk factor is a random variable whose value will be realized during the time $(0, t]$ and will affect the value being measured at time $t$.

In the context of individual tariffs, we define the supplier's VaR for a specific value added service as an estimate of the supplier's loss across the assumed subscriber base, at a given confidence level for a given contract period. The calculated VaR can have a positive or negative value; with the negative value corresponding to a loss. When the value is positive, it should be interpreted as the minimum profit at a certain confidence level from a randomly selected subscriber.

We use the Monte Carlo method to calculate the supplier's VaR [5]. Due to the non-linearity and discontinuity inside the supplier's cost-revenue model: the negotiation results (i.e. the supplier's profits) do not have a linear relationship with the risk factors. Thus the supplier's profit distribution can not be resolved in mathematic formulas but through numerical computation.

The key step in the Monte Carlo method is the randomization of inputs, which should follow a certain distribution. Here the inputs are users' preferences (target points), the distribution is found out by a small scale survey on the same user base. The survey asks the same questions as the PCA survey (see Section 2). The results are users' preferences in the service design space. There are four steps in the Monte Carlo calculation:

Step 1: obtain the empirical distribution of the sample target points in perceptual space.

The corresponding target point coordinates in the perceptual space can be obtained by multiplying the preference data with the PCA loadings. The result is a reduced data set. Each row represents a target point; each column represents one perceived service attribute.

Next, we need to check the correlation between the variables. If all of the variables are independent of each other, the multi-dimensional empirical distribution of the target points can be represented by several statistically independent one-dimensional empirical distributions; each distribution corresponds to a perceived attribute. If correlation exists, we can still check if the multi-dimensional distribution can be represented by lower-dimensional distributions. The worst case is that the distribution can not be reduced to simple forms.

Finally, a description of the distribution is necessary. Non-parametric methods can be used to describe one-dimensional distributions; but the complexity increases significantly as the number of variables increases. For higher dimensional joint distributions, one solution is to use software to do distribution fitting.

Step 2: generate random samples (target points) in perceptual space

Based on the distribution obtained in the previous step, more target points are generated.

In the independent case, we can use the onedimensional empirical distributions to generate more multi-dimensional target points. Each dimension of the target point takes a value generated from the empirical distribution of the user's preference over a perceived attribute. The method to generate these values is as follows: first create a random number generator that provides floating point numbers uniformly distributed between $[0,1]$. Then treat each randomly generated number as a probability and map the probability to the empirical cumulative distribution. The quantile in the cumulative distribution is the random value generated.

In the dependent case, more target points (random samples) can be generated based on the specific distribution using software tools such as Matlab or SPSS.

\section{Step 3: calculate supplier profits}

The randomized target points are fed into our game computational model. For a given supplier's costrevenue model including constraints, and an assumed equilibrium type, we can obtain an empirical distribution of the supplier's profit. (see Figure 4 for an example).

Step 4: calculate VaR

By sorting the supplier's profits we can obtain the cumulative distribution function (CDF). The VaR at a particular confidence level $p$ can be calculated using the $(1-p)$ percentile (quantile) of the CDF. For example, if there are 10000 results, the estimate of the $95 \%$ percentile would correspond to the $500^{\text {th }}$ largest loss, i.e. $(1-0.95)^{*} 10000$. 
In the context of individual tariffs, there are several factors that contribute to the randomness of the supplier's profit: 1) the nature of the distribution of the user's preferences; 2) the variability in the operator's cost and revenue structure; 3) the selection of equilibrium constraints and decision rules.

The first two can not be controlled by the supplier. What the supplier can do is to choose the equilibrium type and change the parameters in the constraints/decision criteria. The effect of the adjustment will be shown in the percentage of equilibria, the expected profit and the VaR. Here the percentage of equilibria gives an indication of the proportion of potential subscribers from the targeted population. The expected profit can be interpreted as the average profit from a randomly selected subscriber. Given a set of decision criteria and a confidence level, if the value of $\mathrm{VaR}>0$, the supplier bears no risk of losing money from the pooled subscribers. However, a $\mathrm{VaR}>0$ does not imply that the supplier always make positive profit from an individual contract. When VaR $<0$, the supplier has risk of losing money from the pooled subscribers; the risk increases as the value of VaR decreases.

If the decision rules and parameters are set in a greedy manner, there will be less equilibria (contracts), higher expected profit and lower risk across the subscriber-base. An opposite strategy will result in more equilibria, lower expected profit and higher risk. The supplier must decide based on the total expected profit and the total risk, and adjust the decision parameters correspondingly.

Of all the parameters in the supplier's constraints and decision criteria, the most important is "minimum profit threshold" (see Section 2). Figure 1a, 1b and 2a give a simplified illustration on how the parameter can affect the percentage of equilibria, the expected profit and the VaR. (In practice, the shape of the curves may be much more complex). Based on an assumed potential subscriber, the supplier can also calculate the total expected profit and total risk, which is illustrate in Figure 2b. An optimal solution where the supplier can achieve maximum profit with minimum risk may not exist. The supplier then must base his decision on the total risk he is willing to take and the total expected profit corresponding to that revenue. Furthermore, the supplier can also adjust other parameters in the constraints and decision criteria to change the shape of the curves.

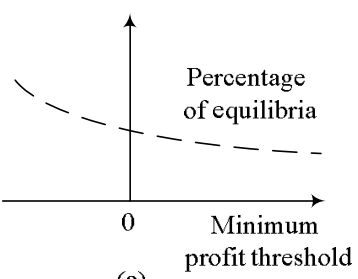

(a)

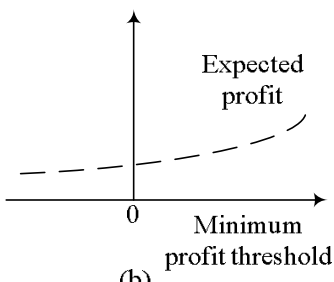

(b)

\section{Figure 1: Profit threshold affects percentage} of equilibria and expected profit

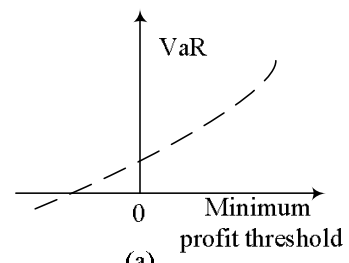

(a)

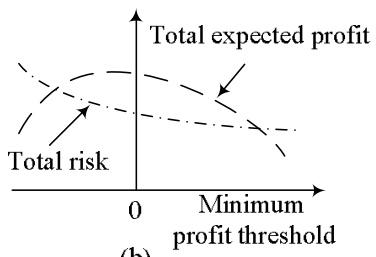

(b)
Figure 2: Profit threshold affects VaR, total expected profit and total risk

\section{Case}

We applied the negotiation model in the context of the fast growing personalized mobile music services. Many operators have already begun to offer mobile music services; some can even be personalized (e.g. in the "Radio DJ" service by Vodafone, user can personalize radio channels according to their own personal tastes), but none of them yet offer personalized tariffs. Our service is called "mobile singing classroom" or "mSining" where the users can improve their singing performance by following the courses and getting instructions and content. Users are students who seek vocal training or want to listen to music via mobiles; the supplier is a mobile operator assisted by music teachers.

The design attributes of the service and the operator's public offer are shown in Table 1. User perceived attributes in the "perceptual space" is found out through a user survey and the PCA method. Our interpretation of the three most important perceived attributes are: the teaching intensity in terms of personal instructions and evaluations; the price performance of raw content in terms of quantity and quality; and the degree of mobility of access to content. A user who wants to take the public offer can sign a contract with the operator directly. The user who wants a personalized service and individual tariff can start to negotiate with the operator. 
Table 1: Service attributes and public offer

\begin{tabular}{|l|c|c|}
\hline \multicolumn{1}{|c|}{ service attributes } & range & $\begin{array}{c}\text { public } \\
\text { offer }\end{array}$ \\
\hline 1. contract period in Month(s) & $1-$ & 4 \\
\hline $\begin{array}{l}\text { 2. degree of use of mobile terminal } \\
\text { from a converged operator }\end{array}$ & $1-10$ & 6 \\
\hline 3. sound quality of music & $1-10$ & 5 \\
\hline $\begin{array}{l}\text { 4. number of evaluations to have } \\
\text { during contract period }\end{array}$ & $0-$ & 4 \\
\hline $\begin{array}{l}\text { 5. number of questions to ask } \\
\text { during contract period }\end{array}$ & $0-$ & 8 \\
\hline $\begin{array}{l}\text { 6. number of songs to download in } \\
\text { total }\end{array}$ & $1-$ & 16 \\
\hline $\begin{array}{l}\text { 7. user's bid for the service for the } \\
\text { whole contract period }\end{array}$ & $10-$ & 200 \\
\hline
\end{tabular}

The negotiations are based on the non-linear supplier model and using the discretized algorithm. Gains and losses (when compared to public tariff) are analyzed. The results can be a win-win or win-lose situation (similar to the results in [1]). The users, as the leader of the game, achieve gains. The operator achieves better results in some cases but becomes worse off in others.

We also carry out calculations when the operator pools a group of user together. We run Monte Carlo simulations under different scenarios. To simplify the calculation, users' preferences are randomized following a multivariate normal distribution in the perceptual space.

We test how the profit threshold would affect the operator's expected profit, VaR etc. The profit thresholds are set to $0,-10,-20$ in different scenarios. Each scenario has about 5000 runs. Figure 3 shows the distribution of users' utility in the equilibria (minimum profit threshold $=0$ ). The dotted line represents the average utility of the users. Figure 4 and 5 shows the operator's profit distribution when minimum profit threshold $=0$, the dotted line represents the operator's average profit. It can be seen from Figure 5 that losses from individual contracts are made. Furthermore, the expected profits are slightly different in Figure 4 and 5. The results of the different scenarios are summarized in Table 2.
Empirical PDF of USER, based on 2486 EQ points @ 20 bins

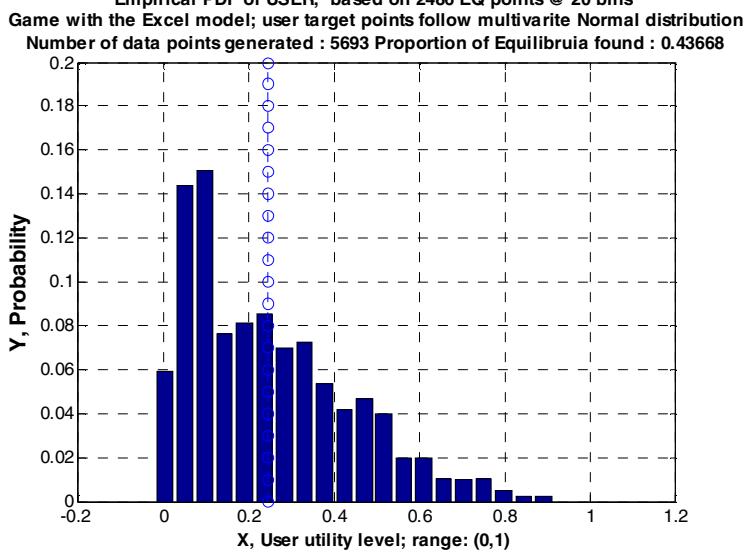

Figure 3: User's utility distribution ( minimum profit threshold $=0$ )

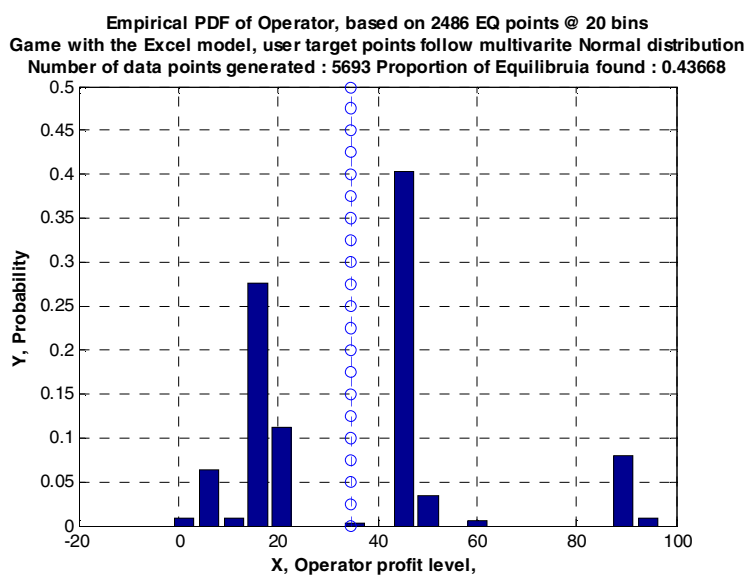

Figure 4: Operator's profit distribution ( minimum profit threshold $=-0$ )

Empirical PDF of Operator, based on 2577 EQ points @ 20 bins Game with the Excel model, user target points follow multivarite Normal distribution Number of data points generated : 5807 Proportion of Equilibruia found : 0.44377

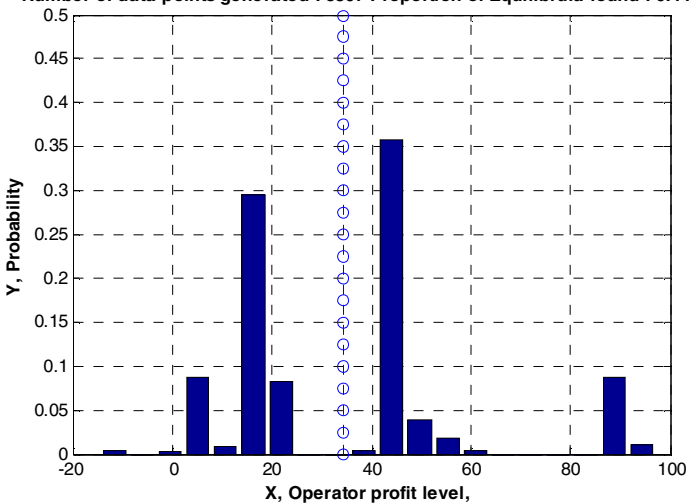

Figure 5: Operator's profit distribution ( minimum profit threshold $=-20$ ) 
By decreasing the profit threshold from 0 to -20 , the percentage of equilibria increases by $0.75 \%$; the users' expected utility increases by $1.2 \%$; the cost is the operator's expected utility (profit), which decreases by $0.49 \%$. The $\mathrm{VaR}$ at $95 \%$ confidence level are all positive, which indicate the operator does not have a risk of making negative profit across the subscriber base. However, the VaR is decreasing much faster $(23 \%)$ than other parameters. For an assumed potential users (e.g. 10000), the total expected profit increases by $1.2 \%$.

Table 2: Results from different scenarios

\begin{tabular}{|l|r|r|}
\hline \multirow{2}{*}{ Equilibria Statistics } & \multicolumn{2}{|c|}{ Profit threshold } \\
\cline { 2 - 3 } & \multicolumn{1}{c|}{$=0$} & $=-20$ \\
\hline Proportion of equilibria & $43.63 \%$ & $44.38 \%$ \\
\hline Expected user utility & 0.242 & 0.245 \\
\hline Expected operator utility & 34.5 & 34.3 \\
\hline VaR @ 95\% confidence level & 7.2 & 5.5 \\
\hline
\end{tabular}

If we decrease the profit threshold further, we can anticipate that the proportion of equilibria will increase further; the operator's expected utility will decrease and risk will increase. But these three variables may change at different speeds; the joint effect can be a non-linear total expected profit curve (or total risk curve); which may be similar to Figure $2 \mathrm{~b}$. Operator then needs to make decision based on the computed curves and his own risk policy.

\section{Conclusion}

This research moves a step further toward the realization of individual tariffs when compared to [1].

The equilibria of the negotiation between one user inside a survey group and an approximately real supplier show that individual tariffs for mobile services can be beneficial to both parties. Furthermore, by allowing for personalization not only at configuration but also at tariff level, the supplier can reduce churn [6], which currently causes huge expenses to the operators.

The risk management approach we introduce allows the supplier to set the parameters of the contract acceptance criteria based on his own risk policy and couples it directly to his mobile and content distribution assets.

Although the tools developed are rather generic and can be used for different classes of services, further work is needed to show the potential of individual tariffs even for basic services packages with very large subscriber numbers, as well as for communities of users (including business communities).

\section{References:}

[1] H. Chen and L.-F. Pau, "Individual Tariffs for Mobile Services: Theoretical Framework and a Computational Case in Mobile Music," presented at International Conference on Mobile Business (ICMB'06), 2006.

[2] H. Chen and L.-F. Pau, "Individual Tariffs for Mobile Communication Services," presented at 16th Biennial Conference of the International Telecommunications Society, Beijing, 2006.

[3] J. M. Lattin, J. D. Carroll, and P. E. Green, Analyzing multivariate data. Pacific Grove, CA: Thomson/Brooks/Cole, 2003.

[4] J. Hull, Options, futures, and other derivatives: Prentice Hall Upper Saddle River, NJ, 2003.

[5] T. J. Linsmeier and N. D. Pearson, Risk Measurement: An Introduction to Value at Risk: University of Illinois at Urbana-Champaign, Dept. of Agricultural and Consumer Economics, 1996.

[6] K. Wieland, "The customer retention challenge," in Telecommunications International, vol. 40, 2006, pp. 8. 


\section{Publications in the Report Series Research ${ }^{*}$ in Management}

\section{ERIM Research Program: "Business Processes, Logistics and Information Systems"}

2007

India: a Case of Fragile Wireless Service and Technology Adoption?

L-F Pau and J. Motiwalla

ERS-2007-011-LIS

http://hdl.handle.net/1765/9043

Some Comments on the Question Whether Co-occurrence Data Should Be Normalized

Ludo Waltman and Nees Jan van Eck

ERS-2007-017-LIS

http://hdl.handle.net/1765/9401

Extended Producer Responsibility in the Aviation Sector

Marisa P. de Brito, Erwin A. van der Laan and Brijan D. Irion

ERS-2007-025-LIS

http://hdl.handle.net/1765/10068

Logistics Information and Knowledge Management Issues in Humanitarian Aid Organizations

Erwin A. van der Laan, Marisa P. de Brito and S. Vermaesen

ERS-2007-026-LIS

http://hdl.handle.net/1765/10071

Bibliometric Mapping of the Computational Intelligence Field

Nees Jan van Eck and Ludo Waltman

ERS-2007-027-LIS

http://hdl.handle.net/1765/10073

Approximating the Randomized Hitting Time Distribution of a Non-stationary Gamma Process

J.B.G. Frenk and R.P. Nicolai

ERS-2007-031-LIS

http://hdl.handle.net/1765/10149

Application of a General Risk Management Model to Portfolio Optimization Problems with Elliptical Distributed Returns for Risk Neutral and Risk Averse Decision Makers

Bahar Kaynar, S. Ilker Birbil and J.B.G. Frenk

ERS-2007-032-LIS

http://hdl.handle.net/1765/10151

Optimal Zone Boundaries for Two-class-based Compact 3D AS/RS

Yugang Yu and M.B.M. de Koster

ERS-2007-034-LIS

http://hdl.handle.net/1765/10180

Portfolios of Exchange Relationships: An Empirical Investigation of an Online Marketplace for IT Services

Uladzimir Radkevitch, Eric van Heck and Otto Koppius

ERS-2007-035-LIS

http://hdl.handle.net/1765/10072

From Closed-Loop to Sustainable Supply Chains: The WEEE case

J. Quariguasi Frota Neto, G. Walther, J.Bloemhof, J.A.E.E van Nunen and T.Spengler

ERS-2007-036-LIS

http://hdl.handle.net/1765/10176 
A Methodology for Assessing Eco-Efficiency in Logistics Networks

J. Quariguasi Frota Neto, G. Walther, J.Bloemhof, J.A.E.E van Nunen and T.Spengler

ERS-2007-037-LIS

http://hdl.handle.net/1765/10177

Strategic and Operational Management of Supplier Involvement in New Product Development: a Contingency Perspective Ferrie E.A. van Echtelt, Finn Wynstra and Arjan J. van Weele

ERS-2007-040-LIS

http://hdl.handle.net/1765/10456

How Will Online Affiliate Marketing Networks Impact Search Engine Rankings?

David Janssen and Eric van Heck

ERS-2007-042-LIS

http://hdl.handle.net/1765/10458

Modelling and Optimizing Imperfect Maintenance of Coatings on Steel Structures

R.P. Nicolai, J.B.G. Frenk and R. Dekker

ERS-2007-043-LIS

http://hdl.handle.net/1765/10455

Human Knowledge Resources and Interorganizational Systems

Mohammed Ibrahim, Pieter Ribbers and Bert Bettonvil

ERS-2007-046-LIS

http://hdl.handle.net/1765/10457

Revenue Management and Demand Ful Ilment: Matching Applications, Models, and Software

Rainer Quante, Herbert Meyr and Moritz Fleischmann

ERS-2007-050-LIS

http://hdl.handle.net/1765/10464

Mass Customization in Wireless Communication Services: Individual Service Bundles and Tariffs

Hong Chen and Louis-Francois Pau

ERS-2007-051-LIS

Individual Tariffs for Mobile Services: Analysis of Operator Business and Risk Consequences

Hong Chen and Louis-Francois Pau

ERS-2007-052-LIS

Individual Tariffs for Mobile Services: Theoretical Framework and a Computational Case in Mobile Music

Hong Chen and Louis-Francois Pau

ERS-2007-053-LIS

Individual Tariffs for Mobile Communication Services

Hong Chen and Louis-Francois Pau

ERS-2007-054-LIS

\footnotetext{
* A complete overview of the ERIM Report Series Research in Management: https://ep.eur.nl/handle/1765/1

ERIM Research Programs:

LIS Business Processes, Logistics and Information Systems

ORG Organizing for Performance

MKT Marketing

F\&A Finance and Accounting

STR Strategy and Entrepreneurship
} 